\title{
Mathematical modeling of diffusion processes of contaminant mixtures in the aquatic environment
}

\author{
R.A. Hasanov \\ Institute of Control Systems of Azerbaijan National Academy of Sciences, Baku, Azerbaijan
}

\begin{tabular}{|c|c|}
\hline $\begin{array}{l}\text { A R T I C L E I N F O } \\
\end{array}$ & A B S T RA C T \\
\hline $\begin{array}{l}\text { Article history: } \\
\text { Received 03.12.2021 } \\
\text { Received in revised form } 13.12 .2021 \\
\text { Accepted } 17.12 .2021 \\
\text { Available online } 29.12 .2021\end{array}$ & $\begin{array}{l}\text { The article considers mathematical models of the processes of } \\
\text { diffusion, dissolution of contaminant mixtures in the aquatic } \\
\text { environment and formation of water quality, as well as the model } \\
\text { of the distribution of contaminant sources throughout the water } \\
\text { basin. The construction of mathematical models that can evaluate }\end{array}$ \\
\hline $\begin{array}{l}\text { Keywords: } \\
\text { Water environment } \\
\text { Natural waters } \\
\text { Cross section of the water basin } \\
\text { Organic substances } \\
\text { Dissolved oxygen }\end{array}$ & $\begin{array}{l}\text { the ability of natural waters to decompose contaminant } \\
\text { components, i.e., the ability of bodies of water to assimilate them, } \\
\text { is studied. }\end{array}$ \\
\hline
\end{tabular}

\section{Introduction}

The aquatic environment is most affected by non-conservative, i.e., organic waste, which is subjected to biochemical oxidation. Decomposition of organic matter in water occurs in a form equivalent to oxidation reactions, leading to a decrease in the concentration of free oxygen dissolved in water, resulting in a disruption of the ecological balance. The amount of dissolved oxygen in water is considered to be one of the main criteria and a general indicator of the viability of the aquatic environment.

\section{General problem statement}

We can write the equation of variation of water volume in unit time in some cross-section $X$ of a water basin (or a large river) as follows:

$$
\frac{\partial Q}{\partial t}+\frac{\partial Q}{\partial x}=Q_{i}+Q_{a f}+Q_{l}
$$

here, $Q_{i}(x, t) ; Q_{a f}(x, t) ; Q_{l}(x, t)$ are groundwater per unit length, surface runoff from the sides, and evaporation, respectively. Let us write the energy balance equation for the elementary volume of the water basin. For energy flow

$$
S=q_{s}+G\left(\beta T_{h}^{4}-e T^{4}\right)+\mathrm{k}^{\prime} \omega\left(T_{h}-\mathrm{T}\right)
$$

here, $\mathrm{e}$ is the mean value of water absorption coefficient, $q_{s}$ is the solar radiation getting in the reservoir during convective heat exchange, $G$ is the Stefan-Boltzmann constant, $\beta$ is the cloudiness

E-mail address: ramingasanov@mail.ru (R.A. Hasanov). 
coefficient of the sky of the water basin, $T_{h}$ is the absolute temperature of the air, $T$ is the water vapor temperature, $k^{\prime}$ is the convection rate, $\omega$ is the speed of the wind. The amount of evaporated water depends on the current meteorological conditions and the current water temperature and can be determined by the following formula $[1,2]$ :

$$
Q_{e}=k^{\prime \prime} \omega\left(e_{s}(\mathrm{~T})-e_{a r}\left(T_{h}, \omega, \ldots\right)\right)
$$

here, $k^{\prime \prime}$ is the $a q^{2}$ components, $e_{s}(T)$ is the intensity of water evaporation at room temperature $T$, $e_{a r}$ is the is the current pressure of water vapor in the atmosphere. Given that the cross section of the water basin is variable $(\Omega(x, t))$, we can write the heat transfer equation as follows:

$$
\frac{\partial T}{\partial t}+v \frac{\partial T}{\partial x}=\frac{-T Q^{\prime}}{\Omega}+\left(Q_{i} T_{i}+Q_{a f} T_{a f}+Q_{e} c_{e} / c_{p}+S l / \rho c_{p}\right) / \Omega
$$

here, $T(x, t)$ is the absolute temperature of water at time $t$ in the cross section $x, c_{p}$ is the heat capacity at constant pressure, $v$ is the velocity of water in a unit cross section.

$$
v=\frac{Q(x, y)}{\Omega(x, y)}, \quad Q^{\prime}=Q_{i}+Q_{a f}+Q_{e}, \quad S=S(T), \quad Q_{i}=Q_{i}(T)
$$

\section{Solution}

If there are strong flows in the water basin (for instance, in rivers), then by discarding the dispersion and diffusion factors in the direction of the flow, we can assume that the mixtures propagate only through the flow. Similarly, we derive equations of similar structure for the amount of oxygen consumed in biochemical reactions $C_{1}(x, t)$, and the amount of free oxygen dissolved in water $C_{2}(x, t)$. Without focusing on intermediate transformations, we obtain the following system of equations to describe the whole process:

$$
\left\{\begin{array}{c}
\frac{\partial Q}{\partial x}+\frac{\partial \Omega}{\partial t}=Q_{i}+Q_{a f}+Q_{l}(T) \\
\frac{\partial T}{\partial t}+v \frac{\partial T}{\partial x}=\frac{-T Q^{\prime}}{\Omega}+\frac{\left(Q_{i} T_{i}+Q_{a f} T_{a f}+Q_{e} c_{e} / c_{p}+S l / \rho c_{p}\right)}{\Omega} \\
\frac{\partial C_{1}}{\partial t}+v \frac{\partial C_{1}}{\partial x}=\frac{\left(Q^{\prime}(T)+k_{s} C_{1}-k_{c}\left(C_{1}, C_{2} T\right)+M+Q_{a f} C_{1 a f}\right)}{\Omega} \\
\frac{\partial C_{2}}{\partial t}+v \frac{\partial C_{2}}{\partial x}=\frac{\left(C_{2} Q^{\prime}(T)+k_{2}(T) l-k_{c}\left(C_{1}, C_{2}, T\right)+N+Q_{a f} C_{2}\right)}{\Omega}
\end{array}\right.
$$

(6) An analytical solution of the system of equations is still impossible. Besides, in order to give an analytical solution, the obvious dependence of expressions that are a function of $T$ must be given in the form of a formula. In many practical problems, such a description is impossible, or more precisely, the results of natural measurements are usually discrete, that is, in the tabular (matrix) form. Therefore, it is more expedient to solve this system by applying numerical methods. It is possible to use existing software packages for this purpose.

For many specific water basins, the model of the problem can be simplified a little. For instance, for the motionless water regime: in this case, $\frac{\partial Q}{\partial t}=0$ and the quantities $Q_{i}, Q_{a f}, Q_{l}$ do not depend on time. Then

$$
\frac{\partial Q}{\partial x}=Q_{i}+Q_{a f}+Q_{l}
$$

The solution of this equation for prismatic water basins can be written as follows: 


$$
Q(x)=Q(0)+\int_{0}^{x}\left(Q_{i}(\xi)+Q_{a f}(\xi)-Q_{l}(\xi)\right) d \xi
$$

When it is possible to calculate the cross-sectional area at each point, we can find the velocity of water in each section by the formula $v(x)=Q(x) / \Omega(x)$. It can be taken as $v(x, t)=v \sin \omega t+$ $v(x)$ in water basins where ebbs and flows are periodic or in large rivers (Kura River, etc.) during snowmelt.

If we assume that the environment is aerobic to a significant degree $K_{c}\left(C_{1}\right)=$ const, then we can formulate the remaining equations of the system in the following typological form:

$$
\frac{\partial u(x, t)}{\partial t}+v(x, t) \frac{\partial u(x, t)}{\partial x}=f(x, t, u)
$$

For this equation, we can reduce the solution of the Cauchy problem to finding the function $u(x, t)$ that satisfies the boundary condition $u(0, t)=u_{l}(t), 0<t<T$ and the initial condition $u(x, 0)=u_{i}(x), 0<x<T$, with $0<x<X, 0<t<T$.

1) Let us consider some typical practical models:

Periodic variation of the mass of water constantly contaminated with organic substances. This is especially true for rivers flowing through a stationary contaminant source. Initial data: $q_{1, s t}-$ contaminant water flow rate, $C_{1, s t} C_{2, s t}-$ composition of the waste, oxygen saturation of river water. The variation of water flow rate in the river can be expressed as follows:

$$
Q(t)=Q_{1}+\Delta Q \cos \omega t
$$

here, $\Delta$ is the volume of contaminated water that periodically enters the water basin at the end of production. Then at the point where the contaminant enters $(x=0)$ :

$$
\begin{gathered}
Q(t)=Q+\Delta Q \cos \omega t, Q=Q_{1}+q_{1, s t} \\
C_{1}(t)=C_{1}(Q, t)=\frac{q_{1} C_{1 s t}}{Q+\Delta Q \cos \omega t} \\
C_{2}(t)=C_{2}(Q, t)=\left(q_{1, s t} C_{2 s t}+\left(Q_{1}+\Delta Q \cos \omega t\right) C_{2 s}\right) /(Q+\Delta Q \cos \omega t)
\end{gathered}
$$

If the water flow rate in the river fluctuates, the flow speed $v(x, t)$ and the cross section $\Omega(x, t)$ are variables. Assuming $\Omega(t)=$ const for a given part, we $v(x, t)=\bar{v}+\Delta v \cos \omega t$.

Here, since $v(x, t)=\frac{d x}{d t}, \frac{d x}{d t}=\bar{v}+\Delta v \cos \omega t$, and we get the solution $x(t)=Q, x(\tau)=$ $0 ; u(\tau)=u_{c}(\tau)$, we get that $x(t, \tau)=v(x-\tau)+\Delta v(\sin \omega t-\sin \omega \tau) / \omega$. Here, $t=\tau$ is the moment when the contaminant mixture reaches the river [3].

If we do not take into account side inflows, filtration and evaporation in the next part of the river, the oxygen demand of biochemical reactions decreases with increasing $x$, and the dependence on $t$ changes with the law of oscillation.

Similarly, for large bodies of water such as a sea, it is possible to determine at what distance from the contaminant source the use of dissolved oxygen in the water will drop to the minimum, and it is possible to determine outside which area the ecological balance is disturbed, i.e., to solve the problem of ecological forecasting.

2) A model for stable water flow rate and organic pollutant load:

If $Q(t)=$ const, then $\mathrm{x}(t)=\bar{v}(t-\tau)$. We denote oxygen deprivation by $\Delta=C_{2 q}-C_{2}$. Then we get

$$
\frac{d C_{1}}{d t}=-k_{1} C_{1}
$$




$$
\begin{aligned}
& \frac{d \Delta}{d t}=-k_{1} C_{1}-k_{2}\left(C_{2 q}-s_{2}\right) . \\
& \quad C_{2 q} \sim \text { a stationary estimate of } C_{2} .
\end{aligned}
$$
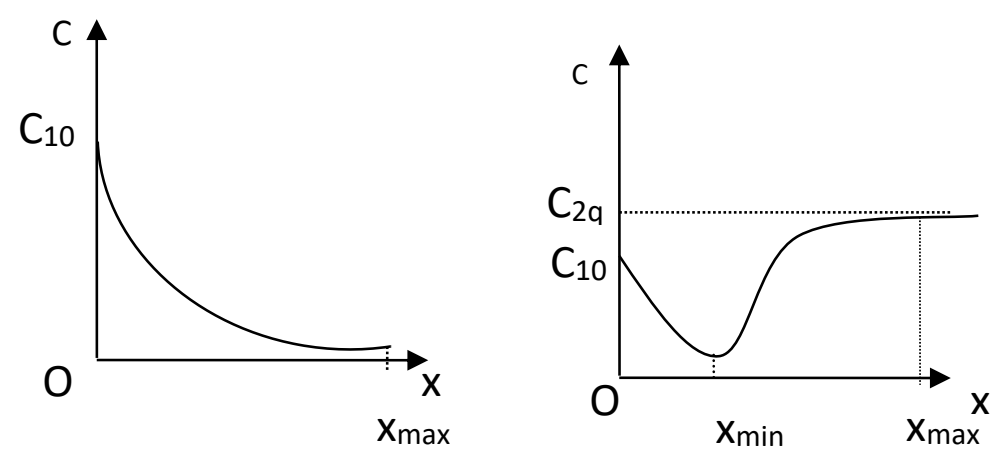

Fig. 1. Variation of $C_{1}$ and $C_{2}$ throughout the river

$$
\begin{gathered}
C_{1}=C_{10} \exp \left(-k_{1} x\right), \\
C_{2}=C_{2 q}-\frac{k_{1} c_{10}}{k_{2}-k_{1}}\left(\exp \left(-k_{1} x\right)-\exp \left(-k_{2} x\right)\right)-\left(C_{2 q}-C_{20}\right) \exp \left(-k_{2} x\right) \\
k_{1}=t^{-1} \ln \left(\frac{C_{10}}{C_{1}(t)}\right)
\end{gathered}
$$

here, $k_{1}=$ const is the mineralization coefficient, $k_{2}=$ const is the natural reaction coefficient. In the general case, we can write the last obtain equations as $Z=F Z$. Here, $Z$ is a vector, $F$ is a matrix. For the case under consideration,

$$
F=\left|\begin{array}{cc}
-k_{1} & 0 \\
k_{1} & -k_{2}
\end{array}\right| \text { is in the form of a determinant. }
$$

Since $F$ is a matrix of constant elements, the plane of states (cases) expressed by the solutions of this equation will also be unique. If $\operatorname{Re}\left(k_{1}, k_{2}\right)>0$, the state will be asymptotically stable. This state is asymptotically stable, since the diagonal elements of the matrix are $-k_{1}$ vo $k_{2}$ here. In any case, $\rightarrow$ $x_{0}, C_{1}=0, \Delta=0$, i.e., the organic mixture is oxidized and the amount of oxygen in the water in the areas $x>x_{0}$ is saturated and the ecological balance is not disturbed in those areas $[4,5]$.

3) Model of the distribution of contaminants throughout the water basin.

If we denote the intensity of distribution of contaminants throughout the water basin by $M(t)$, we can write a model of this process as follows.

$$
\begin{gathered}
\frac{\partial C_{1}}{\partial t}+v \frac{\partial C_{1}}{\partial x}=\frac{k_{1} C_{1}+M(t)}{\Omega(x)} \\
\frac{\partial \Delta}{\partial t}+v \frac{\partial \Delta}{\partial x}=k_{1} C_{1}-k_{2} \Delta
\end{gathered}
$$

We take the initial condition as $C_{1}(x, 0)=0$, and the boundary condition as $C_{1}(0, t)=0$. If we apply the Laplace time transform to the first equation of this system, taking into account the homogeneous initial condition, after a series of mathematical transformations, we get the equation

$$
\frac{d \bar{C}_{1}(x, p)}{d t}=-\left(k_{1}-\frac{p}{v}\right) \bar{C}_{1}(x, p)=\frac{\bar{M}(x, p)}{\Omega(x)} .
$$

Here, $\bar{C}_{1}, M$ are Laplace descriptions of functions of the same name. $p$ is a parameter of the Laplace 
transform. The solution of this equation that satisfies the specified boundary condition is as follows.

$$
\bar{C}_{1}(x, p)=-\frac{\bar{M}(p)}{\Omega^{\prime \prime}(x)\left(p v+k_{1}\right)}\left(1-e^{-\frac{x}{v}\left(k_{1}+p v\right)}\right),
$$

where $\frac{x}{v}$ is the time required for an elementary particle to move to a distance $x$. Applying the inverse Laplace transform, to find $C_{1}(x, t)$, an explicit analytical condition of $M(t)$ must be given. For instance, if $M(t)$ is a unit function, then $\bar{M}(p)=\frac{1}{p}$.

Then:

$$
C_{10}(x, t)=Q^{\prime \prime}(x) \cdot\left(\left(e^{-k_{11} t}-1\right)-2 \sqrt{t} \operatorname{ierfc}\left(\frac{x}{2 v \sqrt{t}}\right) \cdot e^{\frac{x k_{1}}{v}}\right)
$$

If the intensity of the distributed source changes periodically over time, i.e., if $M(t)=$ $M_{0} \sin \omega_{0} t, M_{0}, \omega_{0}=$ const. Then $\bar{M}(p)=\frac{M_{0}}{p^{2}+\omega_{0}^{2}}$ and we find that $C_{1}(x, t)=M_{0} \cdot \sin \omega_{0} t *$ $C_{10}(x, t)$. If $M(t)$ is any specified time function (satisfying the conditions that make it possible to apply the Laplace transform), we obtain the solution as follows:

$$
C_{1}(x, t)=M(t) * C_{10}(x, t) .
$$

Here * is a convolution of functions.

\section{Conclusion}

Mathematical models have been proposed to study the effects of convective diffusion and different flows in the process of transformation in the aquatic environment of contaminant mixtures entering still water basins, and important conditions for solving the problem have been identified.

\section{References}

[1] М. Страшкраба, А. Гнаук, Пресноводные экосистемы, Математическое моделирование, Москва, Мир, (1989) p.376. [In Russian: M. Strashkraba, A. Gnauk, Freshwater ecosystems, Mathematical modeling, Moscow, Mir].

[2] А.И. Шишкин, Основы математического моделирования конвективно-диффузионного переноса примесей, Ленинград, ЛТИ ЦПБ, (1976) p.243. [In Russian: A.I. Shishkin, Fundamentals of mathematical modeling of convective-diffusion transfer of impurities, Leningrad, LTI TsPB].

[3] М.Х. Уртенов, Р.Р. Сеидов, Математические модели электромембранных систем очистки воды: Монография, Краснодар, КубГУ, (2000) p.139. [In Russian: M.Kh. Urtenov, P.P. Seyidov, Mathematical models of electromembrane water purification systems: Monograph, Krasnodar, KubSU].

[4] Г.А. Муратова, Ј.А. Крукиер, О.Б. Никитенко, А.Л. Чикин, И.Н. Шабас, Моделирование гидрофизических процессов в водоеме, В книге «Комплексный мониторинг среды и биоты Азовского бассейна», Апатиты. VI (2004) pp.279-198. [In Russian: G.A. Muratova, L.A. Krukier, O.B. Nikitenko, A.L. Chikin, I.N. Shabas, Modeling of hydrophysical processes in a water body, In the book Integrated monitoring of the environment and biota of the Azov basin, Apatites. VI].

[5] Н.А. Назаров, В.Н. Демидов, Методы и результаты численного моделирования переноса неконсервативной примеси в речном потоке, Водные ресурсы. 28 No.1 (2001) pp.37-46. [In Russian: H.A. Nazarov, V.N. Demidov, Methods and results of numerical modeling of the transport of non-conservative admixtures in a river flow, Vodnyye resursy]. 